\title{
Invited Commentary: Improving the Human Condition Through Rigorous, Applied Developmental Research
}

\author{
Jean E. Rhodes
}

Received: 18 February 2014/ Accepted: 12 March 2014/Published online: 12 April 2014

(C) Springer Science+Business Media New York 2014

\begin{abstract}
This invited commentary describes the shifts toward a more positive characterization of young people over the past 30 years. After describing the new focus on the strengths of young people and the need to ground our understanding in developmental science, it provides an overview of the major contributions of this special issue to the field of positive youth development. Taken together, the groundbreaking work on the 4-H study demonstrates the increasing methodological and statistical sophistication of this strength-based approach.
\end{abstract}

Keywords Development · Adolescents · Positive youth development · History

Thirty years ago, research on adolescence was primarily focused on strategies for treating or preventing negative outcomes, such as delinquency or teenage pregnancy. Young people were cast largely in terms of the problems that they presented to society, and scholarly articles acknowledged the "fear of Americans that they will be victims of violence and crime...[by] "individuals under 25 " (Luks 1984, p. 5). Some studies focused on redressing the "thinking deficits," of "impaired youth," (Roush 1984, 416) and approaches such as Rational Emotive Therapy (RET) figured prominently in the psychological literature. In fact, proponents of RET argued that, "since youth are largely responsible for creating their own emotional and behavioral disturbances, it follows logically that they are

J. E. Rhodes $(\bowtie)$

Department of Psychology, University of Massachusetts, 100

Morrissey Blvd., Boston, MA 02125, USA

e-mail: Jean.Rhodes@umb.edu also responsible for the work required to solve their problems" (Roush 1984, p. 417).

Yet, even at the height of this hand wringing and victim blaming, Lerner and other scholars were planting the seeds of a new approach, one that would focus on the strengths of young people and the need to ground our understanding in developmental science. Indeed, concurrent with the publication of the articles cited above, Kendall, Lerner and Craighead (1984) wrote a prescient Child Development piece in which they encouraged the field to enrich the capacities of young people by providing them with the contexts and capacities "necessary to create actively a good fit for themselves and thus enhance their own further development" (p. 78). In this paper they presented an applied developmental perspective, arguing that, "a marriage may be made between those who study human development and those who intervene to improve the human condition" (p. 77).

As this marriage has matured, so too has the field of positive youth development. With increasing methodological and statistical sophistication, researchers working from within this strength-based approach have sought to identify individual and ecological assets that contribute to positive youth development (PYD). This rigor is exemplified in the important new set of studies that are featured in this special issue. The work stems from the groundbreaking, longitudinal 4-H study, which used a cohort sequential longitudinal design to track over 7,000 youth as they progressed from 5 th through 12 th grade. In addition to measuring traditional markers of risk and well being, the issue includes an important new strategy for measuring positive developmental outcomes. In particular, a wellvalidated tool for measuring PYD and the individual Five Cs (i.e., Competence, Confidence, Connection, Character, and Caring) of PYD is presented. This tool is likely to be widely used in future research and evaluation efforts. 
The issue also includes an unprecedented, longitudinal study of youth out of school time participation, including an analysis of the types and patterns of participation and opportunities that are most beneficial. Another key study expands our conceptualization of parenting styles while focusing on the simultaneous effects of parents and caring non-parent adults on youth development. The results, which suggest that more supportive, authoritative parenting predicts a greater likelihood of a youth's involvement with caring adults, highlights the important compensatory role that programs rich in organized time and, especially, mentoring relationships can play. Other studies underscore the vital role of hopeful expectations and school engagement, while demonstrating the developmental significance of opportunities for volunteerism and engagement in youth programs.

Taken together, the articles in this special issue provide the most solid evidence to date of the proposition that young people are vital resources. Their strengths and competencies can and should be developed over the life span.

\section{References}

Kendall, P. C., Lerner, R. M., \& Craighead, W. E. (1984). Human development and intervention in childhood psychopathology. Child Development, 55, 71-82.

Luks, A. (1984). A new youth movement? Humanist, 44(6), 5-31. Roush, D. W. (1984). Rational emotive therapy for youth: Some new techniques for counselors. Personnel \& Guidance Journal, 84(62), 414.

Jean E. Rhodes is the Frank L. Boyden Professor of Psychology and the Director of the MENTOR/UMass Boston Center for EvidenceBased Mentoring. She obtained her doctorate in clinical psychology from the DePaul University and completed her clinical internship at the University of Chicago. Rhodes has devoted her career to understanding and advancing the role of intergenerational relationships in the social, educational, and career development of disadvantaged youth. 